\title{
Influence of working elements of various configurations on the process of yeast dough kneading
}

\section{Vitalii Rachok}

National University of food Technologies, Kyiv, Ukraine

Keywords:

Kneading

Yeast,

Dough

Intensity

Specific work

Porosity

\section{Article history:}

Received 17.11.2017

Received in revised form

28.12.2017

Accepted 29.03.2018

\section{Corresponding author:}

Vitalii Rachok

E-mail:

RachokV3478@gmail.com

DOI: $10.24263 / 2304-$

974X-2018-7-1-11

\section{Abstract}

Introduction. There was investigated the influence of the geometric parameters of the main working elements on the intensity and quality of the kneading of the yeast dough.

Materials and methods. There was researched the wheat yeast dough, which was mixed by a machine of continuous action using screw, cam and pin work elements. The structural and mechanical properties of the dough were determined by viscosimetry. The porosity of the finished product was determined by analyzing the look of the cut of the finished product and the ImageJ special software package.

Results and discussion. With an increase of indicators of the rate of displacement from 0 to $100 \mathrm{~s}^{-1}$, a prompt jump in the bias voltage from 2000 to $6800 \mathrm{~Pa}$ occurs, then slowly increases to $6950 \mathrm{~Pa}$ in the range of the shift rate from 100 to $800 \mathrm{~s}^{-1}$. As the displacement rate increases from 0 to $800 \mathrm{~s}^{-1}$, the viscosity decreases with degree dependence.

Indicators of the cost of specific work during the kneading of the yeast dough by working elements of various configurations for the parameter of stabilizing grating 2,5\%, reach $22-37 \mathrm{~J} / \mathrm{g}$.

The intensity of kneading the dough depends on the design of the dough kneading machine, the rotational speed of the kneading element and its configuration. Screw working elements are very intense, intensity indicators range from 0.07 to $0.12 \mathrm{~W} / \mathrm{g}$.

The porosity of the bread product after kneading by cam element is $72 \%$ and is a high indicator of the product.

Conclusions. It is confirmed the positive effect of enhanced machine processing by cam and screw working elements during the process of kneading the yeast dough. Pin working elements can be used in combination with a screw element at the beginning of the shaft. A comparative analysis confirms the expediency of using cam-shaped working elements. 


\section{Introduction}

One of the effective methods for acceleration of maturation of the dough and improving the quality of the bakery products is the increased mechanical processing of the dough during the kneading process, which makes it possible to improve the structural and physico-chemical parameters [11]. To reduce the duration of the dough preparation process, there are many different solutions based on biochemical methods of intensifying the maturation of the dough by stimulating the fermentation process and its combination with physical methods of influence to the dough [5]. One such method is the use of intensive mechanical processing of the dough with high-performance working elements [1-3]. The use of new working elements in continuous-action paste machines contributes to a reduction in the length of the dough preparation process [4].

Scientists note the significant influence of the rotational speed of the turning the working elements and their configuration on the intensity of kneading and the quality of finished products in general [12]. Scientific publications indicate that during the kneading of the yeast dough, there is a critical value of the speed of the kneading element and the level of energy expended [8].

One of the effective methods of accelerating the process of kneading the dough and improving the quality of bakery products is the increased mechanical processing of the dough during kneading, which allows to influence its structural-mechanical and physico-chemical parameters [11].

Different influence on the structural and mechanical properties can be achieved by configuring the structural parameters of the working elements in a dough kneading machine of continuous action [5].

The efficiency of kneading is evaluated by a number of indicators, among which the specific work, intensity, productivity, homogeneity of the yeast dough and porosity of the finished product, with the control and observance of rational parameters of the abovementioned indicators, the highest quality bread products are produced [14].

Thanks to many numerical studies provided by Nikolayev M., Auerman L., Goryachova A., Shcherbatenka V., B. Pareyt , K. Brijs, A. Jan it was established that an increase of the mechanical influence on the dough during the kneading affects its rheological properties [1]. The mechanical influence of the nixing element on the dough formed during the kneading, in the first period promotes swelling of proteins and the formation of a spongy gluten framework, which improves the physical properties of the dough [7].

Surveying of screw, pin and cam working elements, which are the most widespread and effective during kneading of dough in dough kneading machines of continuous action.

\section{Materials and methods}

Based on the theoretical search and analysis of existing machines, we have developed a new experimental model. The main research was carried out on a two-camer experimental installation (Figure 1) using a different configuration of working elements: cam, screw and finger work elements.

The object of the study is the process of kneading the yeast dough. The dough is considered as a complex colloidal system, consisting of several continuous and periodic phases. Solids and liquids (gluten and water) in the dough are continuous phases, starch grains and gas formed during the dough fermentation - the periodic phase. As a result, the 
physical properties of the dough are characterized by parameters of solids, liquids and gases, and indicators resulting from the interaction of these phases.

During the kneading the dough, the energy required for the kneading, humidity, time, temperature and dough structure was determined. In the finished product, porosity was determined and the structure of the product examined.

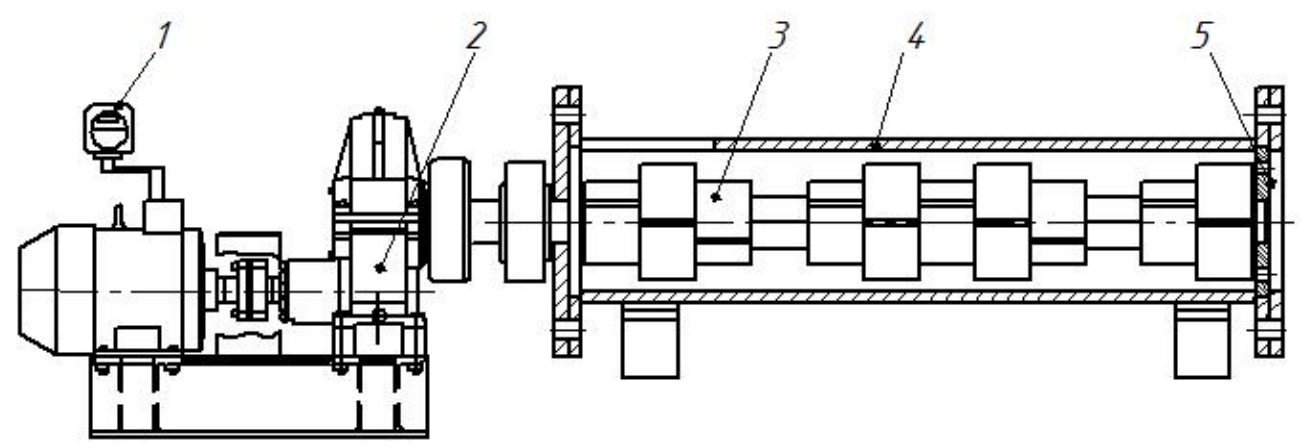

Figure 1. The scheme of an experimental installation with cam operating elements: 1 - a device for measuring electric power; 2 - drive; 3 - working element; 4 - frame; 5 -stabilizing grate.

The power consumed for kneading was determined separately for the working bodies (screw, pin, cam) with a device for measuring the electric power (wattmeter) connected to the motor of the dough kneading machine according to the corresponding scheme.

Specific work $A_{\mathrm{sw}} \mathrm{J} / \mathrm{G}$ was calculated by the formula:

$$
A_{s w}=\frac{\left(N_{\text {general }}-N_{\text {no-load }}\right) \cdot \tau}{Q}
$$

where $\mathrm{N}_{\text {general }}$ - the power consumed by the motor in working condition, $\mathrm{W}$;

$\mathrm{N}_{\text {no-load }}$ - the power of the idling of the corresponding working element, W;

$\tau$ - the time of kneading the dough (the time taken to pass the dough through the working chamber in continuous mode);

The research of rheological and structural-mechanical properties of the dough was carried out using professional equipment, by the method of a rotary viscometry [18,19], and a trinocular bio microscope for the scientific research of Konus Biorex-3 [20].

The structural and mechanical properties of food masses and regularities, as well as the curve of the dough mass flow, was investigated using a viscometer. A sample of the dough was placed in the Reotest viscometer on the measuring cone, a tapered-plate device, installed on the viscometer and secured with a tension ring.

The value of the torque was obtained from the measure during the 12 share rates for different duration of kneading.

The shear stress corresponding to the hydraulic resistance of the wedge-shaped gap depends on the torque $\mathrm{M}$, which is converted into an electrical signal. The shear stress $\tau$ and 
the shear rate $\gamma$ in the wedge-shaped gap are constant. These values were calculated using the formulas given below.

Shear stress:

$$
\tau=\frac{3 M}{2 \pi R^{3}}, \mathrm{~Pa}
$$

where $\mathrm{M}$ - torque, $\mathrm{N} \cdot \mathrm{m}$;

$\mathrm{R}-$ is the radius of the cone, $\mathrm{m}$.

Shear rate:

$$
\gamma=\frac{\omega}{\operatorname{tg} \varphi}, \mathrm{s}^{-1}
$$

where $\omega$ - the angular velocity of the cone rotation, rad;

$\varphi$ - the angle of the slope of the system of the cone-plate system.

Effective viscosity:

$$
\eta=\frac{\tau}{\gamma}, \mathrm{Pa} \cdot \mathrm{s}
$$

To measure the values of rheological parameters on a rotary viscometer, the following correlations are valid:

Shear stress:

$$
\tau=c \cdot a, \mathrm{~Pa}
$$

where $\mathrm{c}$ - the constant value of the cone, $10^{-1} \mathrm{~Pa}$ /gradiatuion of the scale;

$\alpha$ - the value of indicators on the indicator device /gradiatuion of the scale/.

Different types of machines are used to mix the yeast dough, which, depending on the prescription composition and assortment, have different effects on the dough and its maturation. The quality of the dough kneading machines is determined by the quality of the finished product, among which the main indicator is the porosity of the finished product.

To analyze the porosity of the finished products, the tow was cut, photographed and, using the program ImageJ, found the porosity of the finished product and calculated the number of pores. ImageJ is an image processing program where you can calculate the area and level of detail of an image, statistics of user-defined selections, measure distances and angles, create density histograms and profile sections of the plot.

The solving the problem of intensifying the process of kneading under continuous tasting can be solved by applying cam, screw and pin working elements [17].

The cam (Figure 3), screw (Figure 4), pin working element (Figure 5) and their influence during the kneading on the quality of the semi-finished product and the finished product were studied. The step of the working element, was being changed and the plane of the living section was being adjusted at the outlet of the yeast dough after kneading. 


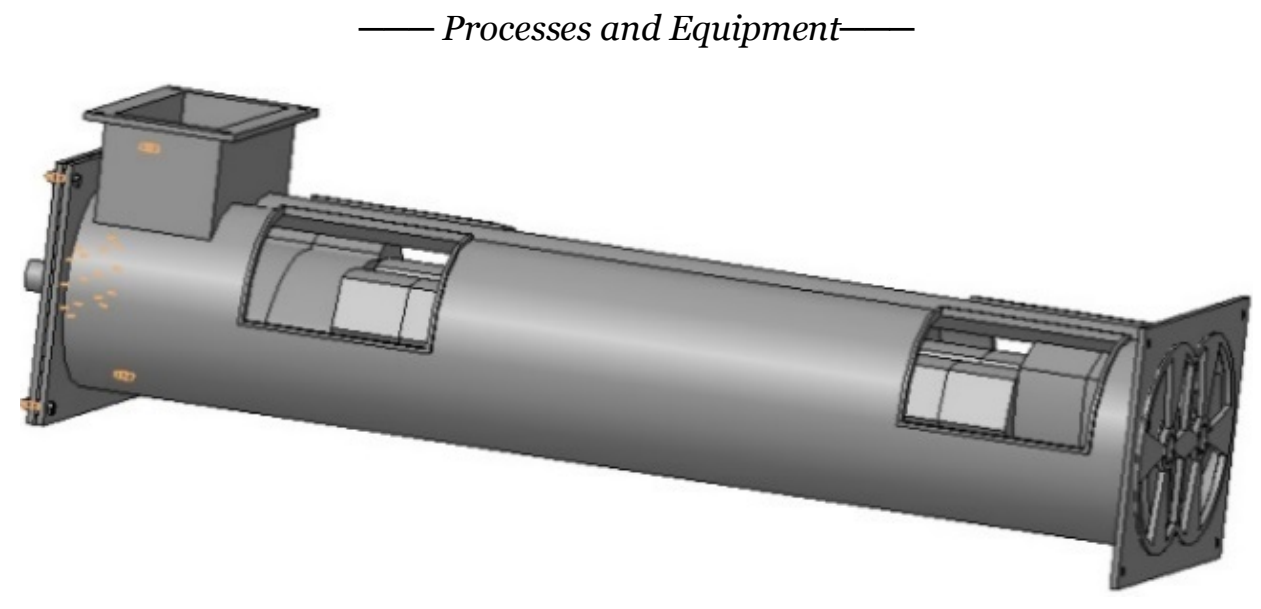

Figure 2. 3D Model of experimental installation with cam working elements inside

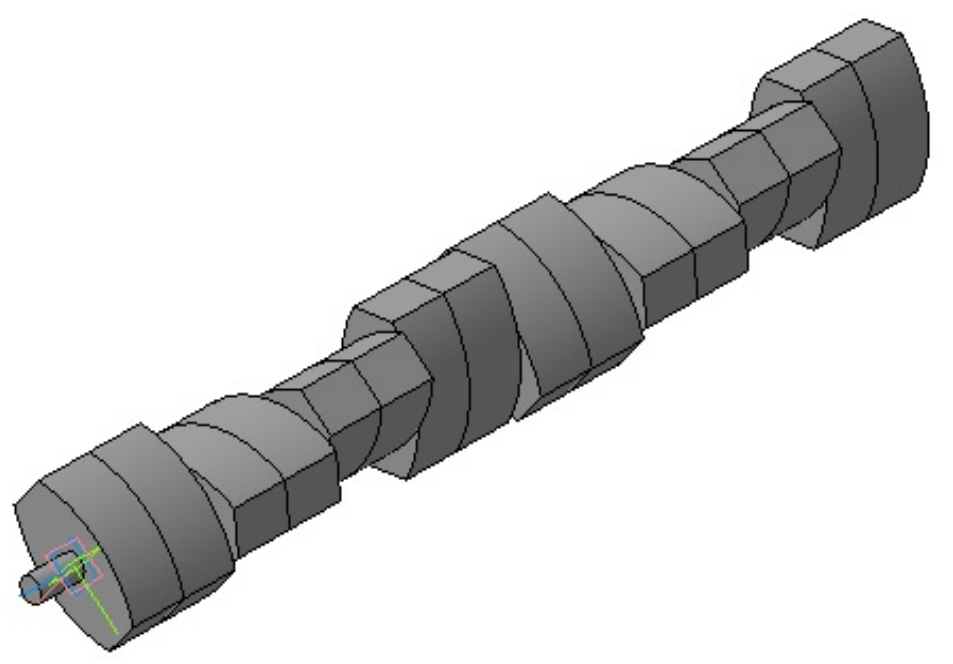

Figure 3. Cam working element 


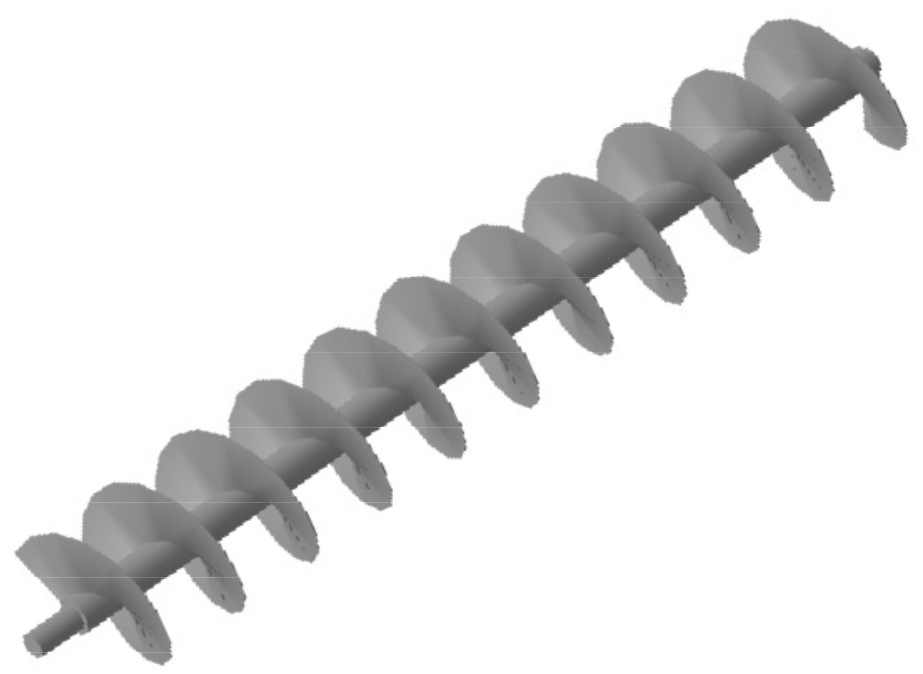

Figure 4. Screw working element

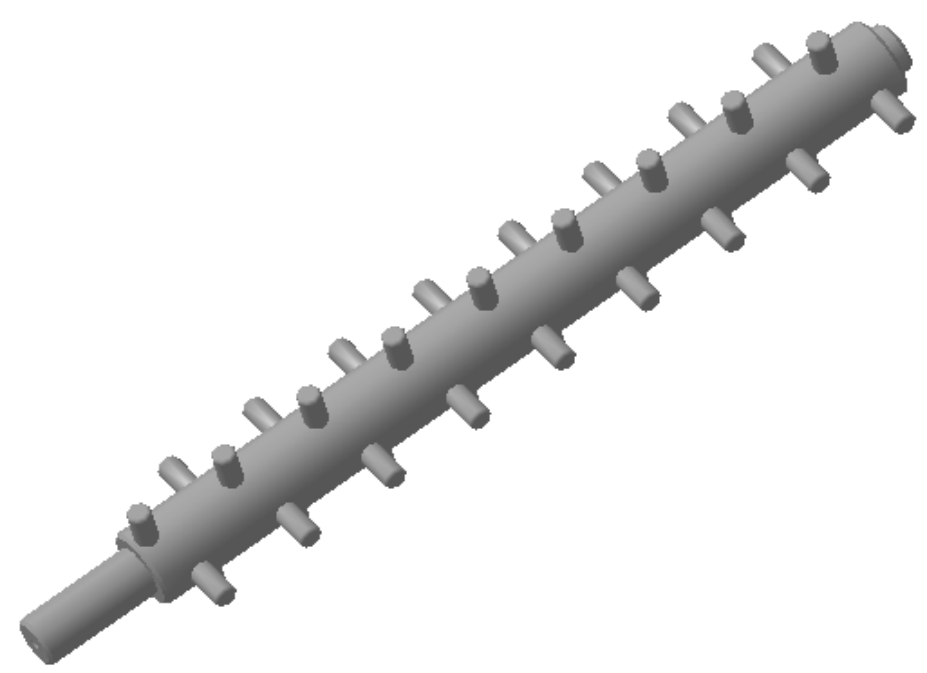

Figure 5. Pin working element

The choice of the construction of technological equipment and optimal modes of processing food products depends on the structural and mechanical properties of raw materials, which are determined by the chemical and biochemical composition and the internal structure of the material. 
During the kneading the formation of the dough occurs as a result of a number of processes, of which the most important are: physical-mechanical, colloidal and biochemical processes. All these processes take place at the same time, mutually affect each other and depend on the duration of kneading, the temperature and the quantity and quality of the raw material used during kneading the dough.

Physical-mechanical processes take place during a kneading under the influence of a kneading element which mixes particles of flour, water, yeast suspension and solutions of raw materials, providing the interaction of all the constituents of the components of the formulation.

The dipped the dough should ensure the equable kneading of all components, obtaining a dough with homogeneous properties and creating optimal conditions for further stages of the technological process: fermentation, separation, stamping and baking.

\section{Result and discussion}

The coloration between the force acting on the dough and the strain caused by its action is investigated.

The yeast dough is a micro heterogeneous disperse system. In the process of processing, raw materials and semi-finished products are stretched, compressed, that is, they are in a complex stressed state. The kneading of the yeast dough is due to the flow of the material, which is described by the relevant laws.

To describe the process of kneading the dough, it is necessary to know the properties of the viscosity and consistency of the dough. Consistency, as a complex term, characterizes the mechanical properties in the material volume - shear rate, shear stress, viscosity, and also the properties of adhesion and adhesiveness.

Structural-mechanical properties characterize the ability of the material to hold and change the shape (deformed) under the influence of external forces.

Depending on its condition and the conditions of loading, various orthogonal properties are manifested in varying degrees.

The obtained results allow us to construct a curve of the dough flow during kneading the yeast dough with different constructive, working elements (Figure 6). The researches have established, within the studied range, the test weight does not change the nature of the flow regardless of the time interval of measurements.

The homogeneous structure of the dough at the stage of plasticization is a stable system and the change in the rate of displacement immediately leads the system to a new structural state. The processes of destruction and restoration of the structure are in the studied range of shear rate in an equally weighted state. The curve of the current with sufficient probability is of a power degree.

The non-Newtonian bodies are characterized by effective viscosity, namely, the coloration of the strain of shear to the shear rate. Scientists argued that effective viscosity acts as a structural and mechanical barrier in the formation and destruction of a foamy porous structure [14]. In the case of insufficient high viscosity, the formation of the gas phase and the gas pores in the volume of the dough occurs during its kneading, and fermentation with low energy consumption. 


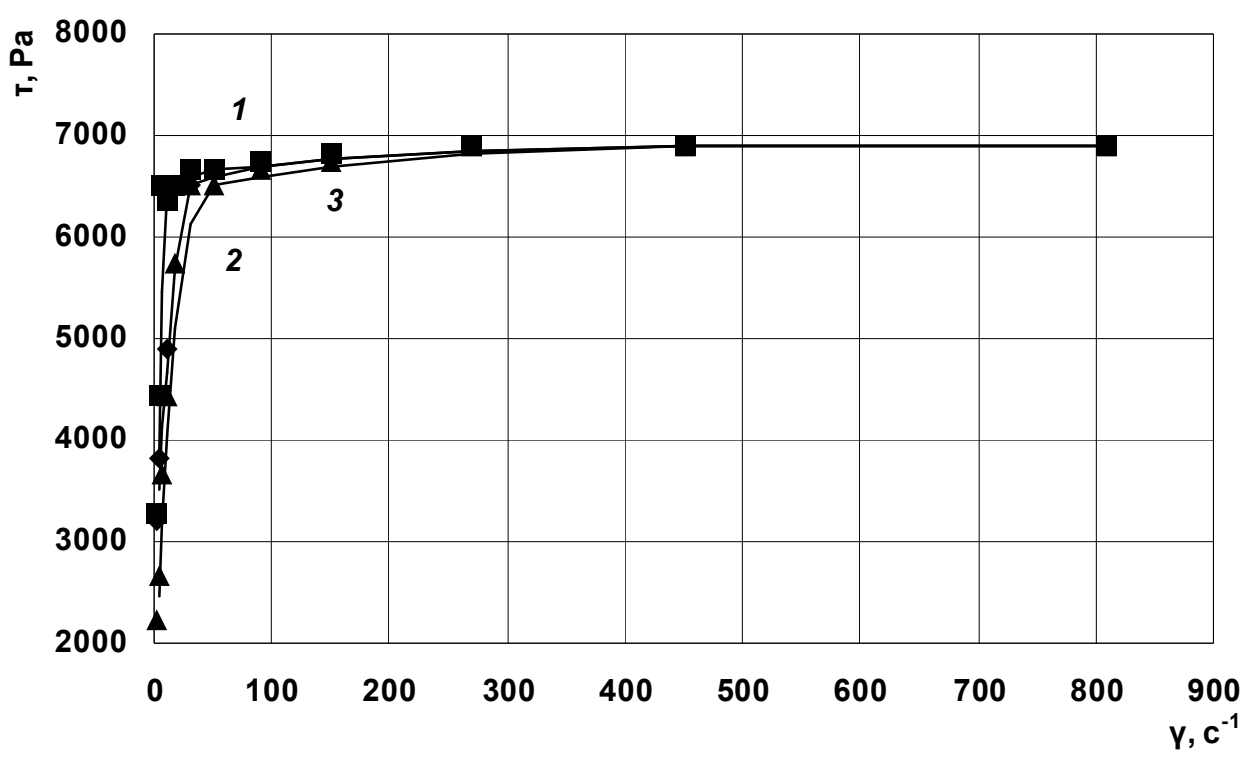

Figure 6. Experimental curve of dough flow during kneading of yeast dough with working elements of various configurations (1-cam element, 2-screw element, 3-pin element)

The obtained experimental data allow us to obtain a change in the effective viscosity of the dough during kneading and its dependence on the shear rate, which confirms the nonNewtonian character of the curve of the dough flow during the kneading of the dough with the working elements of different configurations (Figure 7).

With an increase in the shear rate, the effective viscosity values are significantly reduced. At low viscosity, porous walls are easily destroyed by excessive pressure of gaseous products. The kneading of the yeast dough should be carried out at high viscosity, in this case no fine-grained structure will be observed and the volume of bread is increased.

After 1-2 minutes after kneading, the kneading of the raw material is transferred to the condition of the bound mass. During the subsequent kneading as a result of processes of swelling and action of hydrolytic enzymes, the test substance acquires a certain elasticity. After 4-5 minutes of kneading of the yeast dough as a result of deepening processes of enzymatic and mechanical disaggregation of proteins, which prevail during this period of the processes of swelling, there is a gradual dilution of the consistency of the dough.

The magnitude of the specific work is indicative and does not have a strictly separated number, since it can vary on the same machine depending on the length of the dough and the structural parameters of the working elements.

Determination of the energy is necessary for calculating the dough kneading machine and energy analysis of individual stages of dipping, improving the mechanism of the process and justifying the rational parameters of the individual stages of dipping. In most modern dough kneading machines, the batch is made as a result of the rotational movement of one or more shaft blades. 


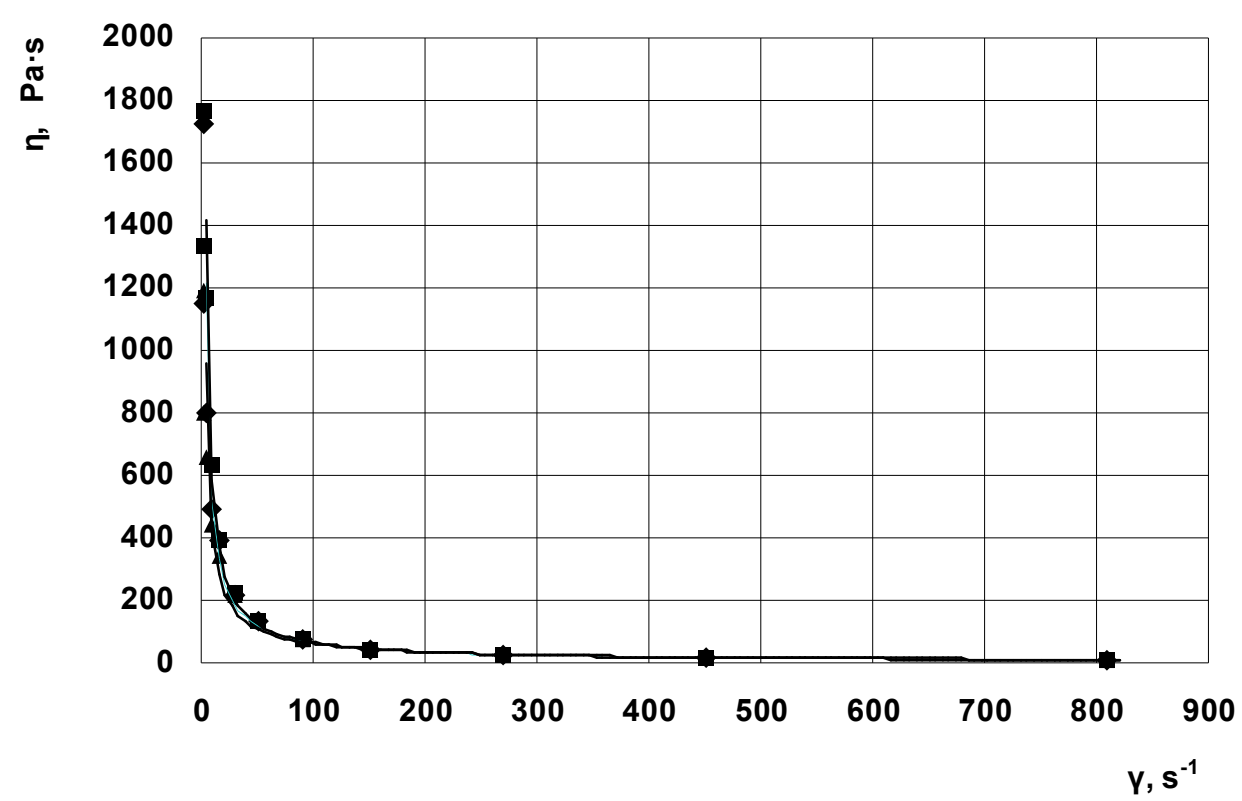

Figure 7. Dependence of the effective viscosity of the dough on the shear rate during kneading the yeast dough with the working elements of different configurations

The obtained experimental data was processed according to the above-mentioned method, calculated according to the formula and reduced to the histogram (Figure 8) depending on the specific work using the working elements of different configurations and the living section of the stabilizing lattice, through which the dense yeast dough is released.

The research was carried out at a living section of the stabilizing grating: $2,5-5,1-7,6 \%$ of the total grating area, this is the percentage of the hole through which the bound yeast dough is obtained, to the total grating area.

High indicators of specific work costs are observed during the kneading the yeast dough with the working elements of various configurations for the stabilizing lattice parameter of $2.5 \%$; the performance of the specific work reaches $22-37 \mathrm{~J} / \mathrm{g}$. The highest values $(37 \mathrm{~J} / \mathrm{g})$ are achieved during the kneading the cam operating elements, for such parameters the dough-machine of continuous action can be attributed to super-fast dough machines, intensive action. With the increase in the real section of the stabilizing grate, the costs of the specific work are reduced, this is due to a decrease in the time of kneading and rapid passage of the dough through the stirring chamber. During the using pin work elements there are indicators of specific work in the range of 2 to $7 \mathrm{~J} / \mathrm{g}$ for such parameters, the dough machine is classified as low-speed, with the exception of kneading with the finger working elements for the value of the live section of the lattice $2,5 \%$, for such parameters the specific work reaches the mark in $22 \mathrm{~J} / \mathrm{g}$ in this case, the car is classified as high-speed. For use in the dough machine screw working elements, it can be attributed to high-speed, as the performance of the specific work in this case reaches $18-25 \mathrm{~J} / \mathrm{g}$. 


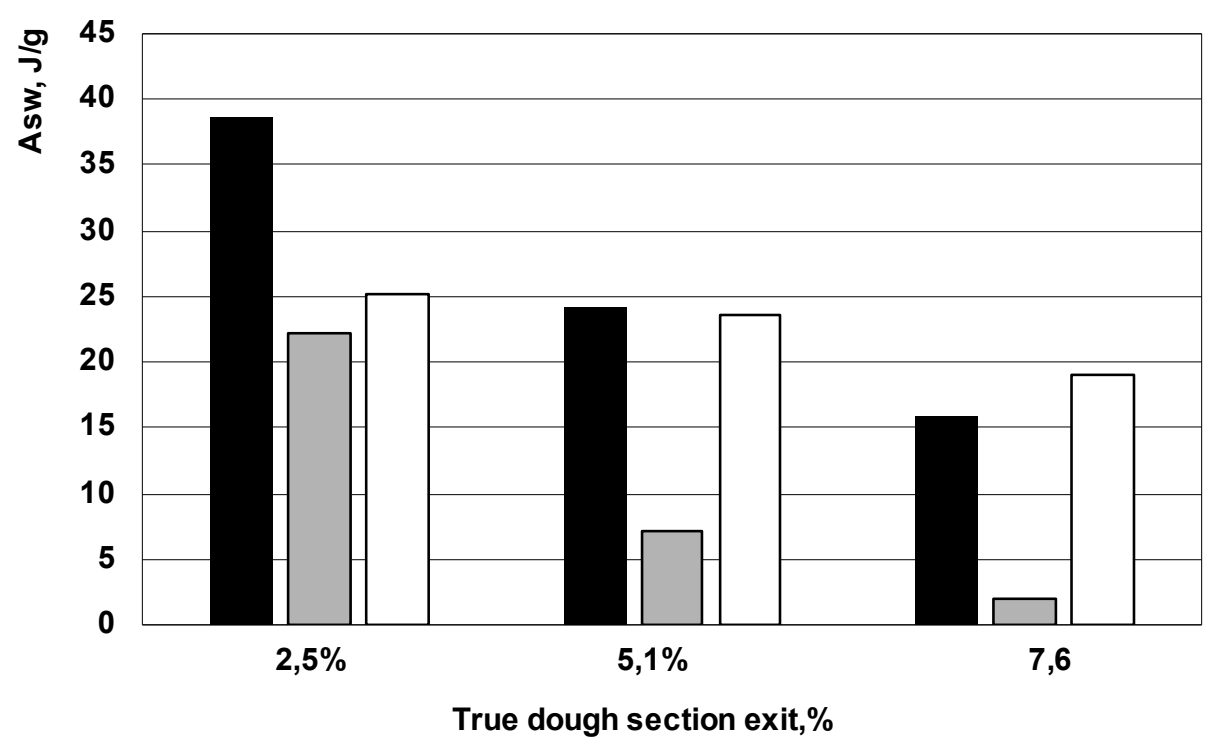

\begin{abstract}
$\square$ Cam element $\square$ Screw element $\quad \square$ Pin element
Figure 8. Dependence of specific work on the use of working elements of various configurations and the real section of the stabilizing grate
\end{abstract}

Thus, the cost of specific work depends on a number of factors that affect the process of kneading the yeast dough, to achieve the necessary values of the cost of specific work, can be achieved by adjusting the variables in the dough machine, such as the working element, the cross section of the stabilizing lattice, the speed of rotation of the working element. The higher the cost of specific work, the better and high-quality the yeast dough after kneading. Strengthened mechanical treatment of the dough while baking causes intensification of maturation of the dough after meal, that is, reducing the duration of maturation of the dough and improving its quality.

The intensity of kneading the dough depends on the design of the dough machine, the rotational speed of the kneading element and its configuration.

The intensity of the kneading (Figure 9) is characterized by the amount of work expended per unit of working time, that is, the average useful power of the drive P, which falls on a batch of $1 \mathrm{~g}$ of the test and is determined by the formula:

$$
U=A_{s w} / \tau
$$

where $A_{s w}$ - specific work, $\mathrm{J} / \mathrm{G}$;

$\tau-$ the duration of dipping, s. 


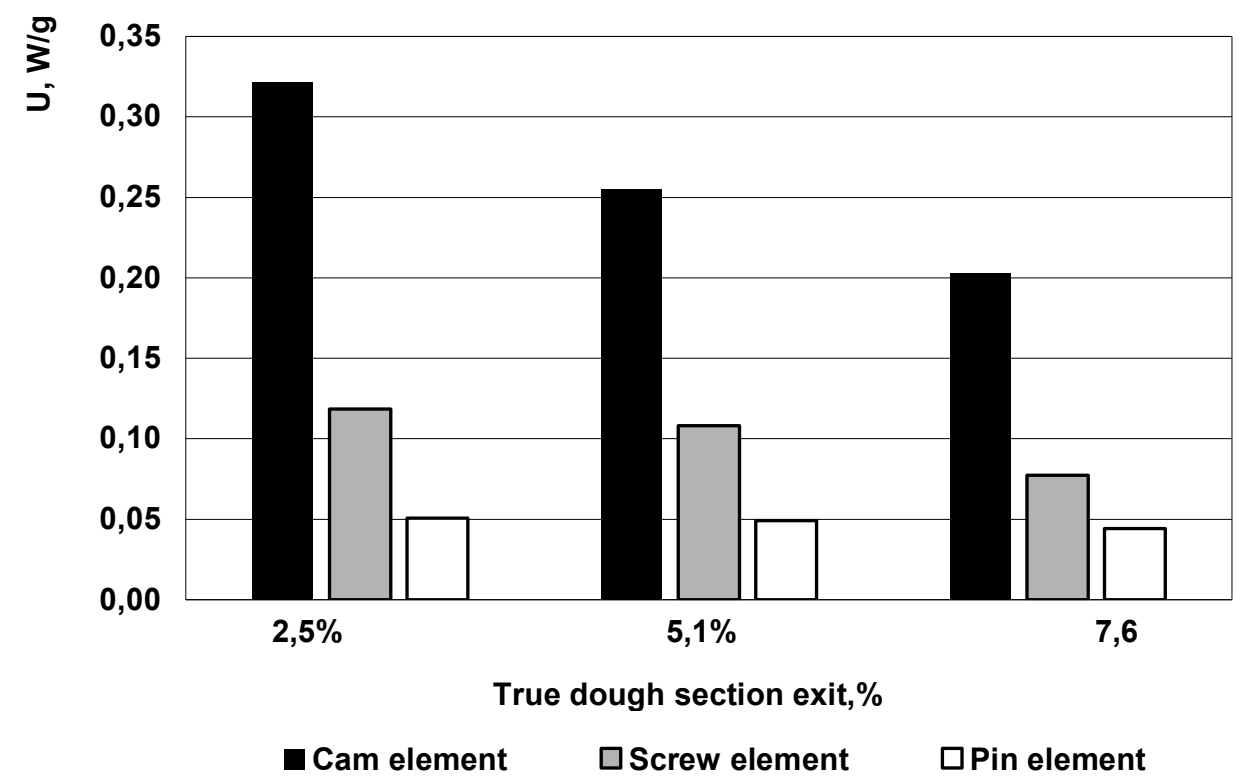

Figure 9. Intensity of the process of kneading using the working elements of different configurations and the living section of the stabilizing grate

During the search the screw working element showed the best intensity of the process of kneading the yeast dough on a continuous machine of continuous action and analyzing the obtained data, it can be argued that the most intensive batch $(0,2-0,33 \mathrm{~W} / \mathrm{g})$ for the use of cam work elements and in a short time, the semi-finished product is transported quickly. In the case of performance machining by cam operating elements, more energy is consumed, as a result, the quality of the yeast dough improves, due to the fact that the macromolecules of gluten under the influence of stresses occurring in the dough are partially destroyed, but due to the internal restructuring of the structure, the gluten is again restored acquires elasticity and elasticity. In the process of kneading the dough with the cam working elements, there is an accelerated swelling of the proteins and the formation of a gluten-free frame, resulting in the dough gaining elasticity, and its physical properties are improved. Screw working elements are very intense, intensity indicators range from 0.07 to $0.12 \mathrm{~W} / \mathrm{g}$. Not intense are considered as pin working elements, the intensity indicator in them at any plane of the living section reaches marks less than $0.05 \mathrm{~W} / \mathrm{g}$. 


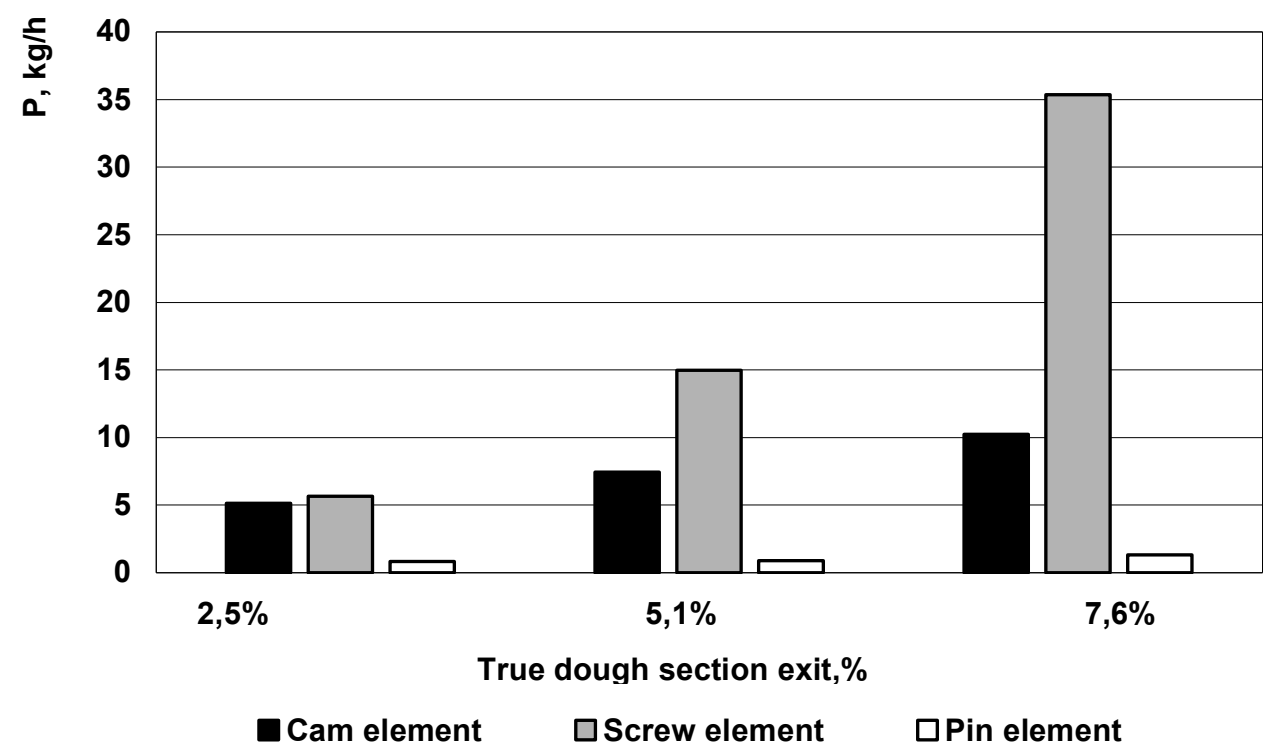

Figure 10. Performance of a dough machine of continuous action for different working constructive elements

During the search, the cam working element was the most productive, indicators at the area of the test section yield $7.6 \%$, reaching the mark of $35.7 \mathrm{~kg} / \mathrm{h}$, this pattern is explained by the fact that the structural screw elements have good transporting ability and in a short time transported semi-finished products. The cam elements have a transport capability in the range of 5 to $11 \mathrm{~kg} / \mathrm{h}$, due to the fact that most of the work is spent on the batch, rather than on transportation. Pin working elements do not have transporting properties and can only be used in a combined working element, where in the beginning there will be several turns of the screw.

The porosity of the finished product is the volume of pores, expressed as a percentage of the total volume of crumb of bread. Bread with uniform fine porosity, well loosened is better impregnated with digestive juices and therefore is better absorbed.

An important indicator of the quality of the finished product is porosity. The porosity of the bread products is aimed at a large number of pores, even in size and in the nature of the distribution of the product. During wearing out the formation of porosity of products, a significant increase in the amount of gas in the pores of the preform determines the growth of volume during baking. Optimum conditions of production provide a larger volume of products, a soft, well-developed porosity.

The configuration of the working element directly affects the kneading of the yeast dough, and as a result the quality of the finished product: the surface condition and the structure of porosity from the gas-filled dough.

The structure of the bread product was investigated, a detailed analysis of the breadcrumbs of bread was carried out, and after the mathematical processing of the obtained data, porosity was determined (Figure 11) after kneading the yeast dough, working elements of different configurations. 
Model photo
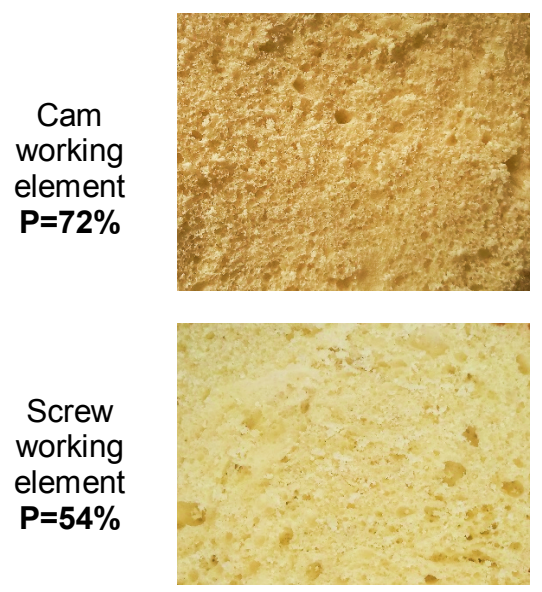

Pin working element $\mathrm{P}=\mathbf{4 8 \%}$
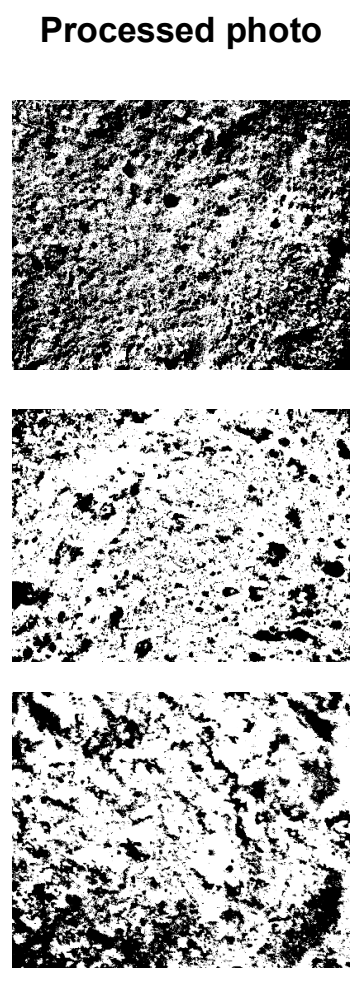

Structure of porosity
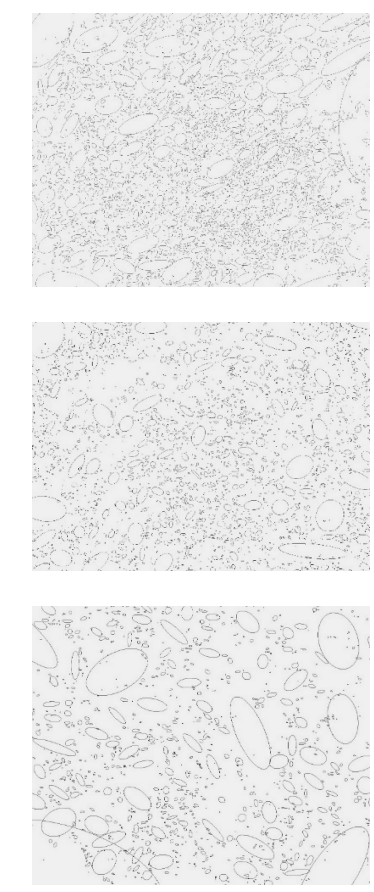

Figure 11. Porosity of the bread product after kneading the yeast dough with various structural elements

The fine grained structure of the porosity of the wheat bread product from wheat yeast dough is observed during the kneading by cam working elements, the percentage of porosity in this case is $72 \%$ and is a high indicator for this type of product. After kneading with the screw working element, the porosity is observed in the range of $54 \%$, the index is much lower than in the case of a cam working element, the difference is due to the lower cost of the specific work required for the dough kneading. During the kneading by a screw working element, the number of pores decreases and the existing pores increase in volume. The structure of the bread product mixed by the pin work element is unbalanced and has a low porosity of $48 \%$, the thickness of the pore wall is formed during plasticization, and when porosity develops, only the merging and rearrangement of gas in larger pores occurs with the previous wall thickness, so as the design parameters of the pin working elements do not provide qualitative plasticization, then there is a low porosity of the finished product. 


\section{Conclusion}

The conducted studies confirm the positive effect of enhanced mechanical processing of the dough during the kneading process. Due to the use of continuous action elements, the process of kneading the yeast dough is intensified, which makes it possible to shorten the dough fermentation period before processing.

The conducted comparative analysis confirms the expediency of using cam-working elements. Screw working elements, have good transporting properties and are highly productive during the use. The use of pin working elements is appropriate in combination with screw working elements at the beginning of the screw, such working element will allow to mix in the beginning and subsequently transport the semi-finished product, then the actual masonry and plasticization will be carried out at the expense of the pin working elements.

In case of application of the cam working elements, an intensive kneading the yeast dough takes place and high porosity indicators of the finished product are observed.

Studies have confirmed that at the same time and intensity and duration of dipping affect the value of the share of specific work. Intensity, in turn, depends on the frequency of rotation of the worm shaft and the mechanism of its impact on the dough, that is, the construction of the dough machine. Thus, at the same intensity, a variety of specific work can be obtained by varying the duration of dipping and achieving the required parameters of the structural and mechanical properties of the dough and the high porosity of the finished product.

\section{References}

1. Pareyt B., Brijs K., Jan A. Delcour (2013), Impact of kneading time and sodium stearoyl lactylate on gluten polymerization during baking of wheat flour dough, Food Chemistry, 141, pp. 4179-4185.

2. Hailemariam L., Okos M., Campanella O. (2007), A mathematical model for the isothermal growth of bubbles in wheat dough, Journal of Food Engineering, (82), pp. 466-477.

3. A.Shehzad, Chiron H., Della Valle G., Lamrini B., Lourdin D. (2012), Energetical and rheological approaches of wheat flour dough kneading with a spiral mixer, Journal of Food Engineering, 110, pp. 60-70.

4. Zeppelin Reimelt GmbH (2013), A suitable solution for every kneading task, Mixing Technology, Available at: http://www.zeppelin-systems.com/en/productssolutions/mixers.html.

5. Connelly R.K., Kokini J.L. (2007), Examination of the kneading ability of single and twin screw mixers using 2D finite element method simulation with particle tracking, Journal of Food Engineering, 79, pp. 956-969.

6. Iedema P.D., Remerie K., M. van der Hamb (2011), Controlled peroxide-induced degradation of polypropylene in a twin-screw extruder: Change of molecular weight distribution under conditions controlled by microkneading, Chemical Engineering Science, 66, pp. 5474-5486.

7. Mani K., Eliasson A. C., Lindahl L., Tragardh C. (1992), Rheological properties and bread making quality of wheat flour doughs made with different dough mixers, Cereal Chem., 69(2), pp. 222-225. 
8. Mitchell T.A. (1984), Dough mixer controls for the mechanical dough development process, Proceedings of the International Symposium on Advances in Baking Science and Technology, Kansas State University, Manhattan.

9. Wooding A.R., Martin R.J., Wilson A.J., MacRitchie F. (1994), Effect of sulphurnitrogen treat-ments on work input requirements for dough kneading on second season, Proc. 44th RACI Cereal Chemistry Conference.

10. Uchida K., Okamoto K. (2008), Measurement technique on the diffusion coefficient of powder flow in a screw feeder by X-ray visualization, Powder Technology, 187, pp. $138-145$

11. Chin N., Campbell G. (2005), Dough aeration and rheology: Part 1. Effects of kneading speed and headspace pressure on mechanical development of bread dough, Journal of the Science of Food and Agriculture, 85, pp. 2184-2193.

12. Shehzad A., Chiron H., Della Valle G., Lamrini B. (2012), Energetical and rheological approaches of wheat flour dough kneading with a spiral mixer, Journal of Food Engineering, 110, pp. 60-70.

13. Haraszia R., Larroqueb O.R., Butowb B.J. (2008), Differential kneading action effects on functional properties and polymeric protein size distribution of wheat dough, Journal of Cereal Science, 47, pp. 41-51

14. Jekle M., Becker T. (2011), Dough microstructure: Novel analysis by quantification using confocal laser scanning microscopy, Food Research International, 44, pp. 984-991.

15. Kudinova O., Kravchenko O., Lytovchenko I. (2014), Modelling of process in twinscrew dough-kneading machines, Journal of Food and Packaging Science, Technique and Technologies, 5, pp. 64-68.

16. Telychkun Yu., Telychkun V, Kravchenko O. (2013), Perspective direction of complex improvement of rusk wares, Journal of Food and Packaging Science, Technique and Technologies, 2. pp. 67-70.

17. Klemens Kohlgruber (2008), Co-Rotating Twin-Screw Extruders, Bayer Technology Services, 347, pp. 152-158.

18. Dobraszczyk B. (2016), Analysis of Dough Rheology in Breadmaking. Encyclopedia of Food Grains, Elsevier, pp. 343-353

19. M. Morgensternb O. Campanellacfl N. Larsenb (2000), Rheological Properties of Dough During Mechanical Dough Development, Journal of Cereal Science, pp. 293-306

20. P. Kruit, R. G. Hobbs, C-S. Kim (2016), Designs for a quantum electron microscope, Ultramicroscopy, 164, pp. 31-45 